\title{
BIOELECTRICIDAD GENERADA EN CELDAS DE COMBUSTIBLE MICROBIANA A PARTIR DE DIFERENTES SUBSTRATOS FERMENTADOS
}

\author{
BIOELECTRICITY GENERATED IN MICROBIAL FUEL CELLS FROM \\ DIFFERENT FERMENTED SUBSTRATES
}

\author{
Daladier Castillo Cotrina ${ }^{1}$, \\ Carlos Tito Vargas ${ }^{2}$
}

\section{RESUMEN}

Se tuvo como objetivo generar electricidad en celdas de combustible microbiana utilizando células de Saccharomyces cerevisiae y sacarosa como sustrato. Se utilizó un sistema de dos cámaras, como celda de combustible microbiana (MFC). En una de las cámaras llamada anódica se colocó una suspensión de S. cerevisiae $0,4 \%(\mathrm{p} / \mathrm{V})$ conteniendo sacarosa $4 \%$. En la otra cámara llamada catódica se colocó agua destilada y se le aireó a razón de 1 VVM. La experimentación en la MFC se realizó a temperatura ambiente durante $35 \mathrm{~h}$. La toma de datos de la generación de electricidad fue con un multímetro. Se hizo evaluaciones a las $0,5,10,15$, $20,25,30$ y $35 \mathrm{~h}$. Haciendo toma de datos a su vez, para cada evaluación, en los valores de resistencia de 0 (asumiendo como resistencia al aire para este valor), 10, 20, 50, 200, 500, $1000,2000,10000,40000$ y 100000 ohmios. Se obtuvo un voltaje máximo de $219,7 \mathrm{mV}$ sin utilizar resistencia de corriente, a temperatura ambiente y a las $10 \mathrm{~h}$ del lapso de $35 \mathrm{~h}$ en que duró la experimentación; así mismo se determinó un área de polarización, relacionando gráficamente la densidad de potencia vs. densidad de corriente, entre las 20 y $80 \mathrm{~h}$ de experimentación en la cual evidenció: en el límite superior, un valor tope más alto de la curva obtenida a las $20 \mathrm{~h}$ correspondiente a una densidad de potencia de $5000 \mathrm{E}-2 \mathrm{~mW} / \mathrm{m}^{2}$ y de densidad de corriente de $40 \mathrm{E}-2 \mathrm{~mA} / \mathrm{m}^{2}$; y en el límite inferior, un valor tope más alto de la curva obtenida a las $0 \mathrm{~h}$ correspondiente a una densidad de potencia de $600 \mathrm{E}-2 \mathrm{~mW} / \mathrm{m}^{2}$ y de densidad de corriente de $35 \mathrm{E}-2 \mathrm{~mA} / \mathrm{m}^{2}$.

Palabras clave: bioelectricidad; Sacharomyces cerevisiae, heterofrófica, fermentación

\section{ABSTRACT}

The aim was to generate electricity in microbial fuel cells using Saccharomyces cerevisiae cells and sucrose as substrate. A system of two cameras was used as microbial fuel cell (MFC). In one chamber called anodic suspension of $\mathrm{S}$. cerevisiae $0,4 \%(\mathrm{w} / \mathrm{v})$ containing $4 \%$ sucrose was placed. In the other chamber called cathodic distilled water was placed and was aerated at 1 VVM. Experimentation in MFC was performed at room temperature for $35 \mathrm{~h}$. The data collection of electricity generation was with a multimeter. Assessments were made at $0,5,10,15$ , 20, 25, 30 and $35 \mathrm{~h}$. At each evaluation data was taken in the resistance values of $0,10,20,50$, $200,500,1000,2000,10000,40000$ and 100,000 ohms. A maximum voltage of 219,7 mV was

\footnotetext{
${ }^{1}$ Dr. En Ciencias ambientales, Maestro en Ciencias con mención en Microbiología y Biotecnología, Biólogo Microbiólogo. Facultad de Ciencias. Universidad Nacional Jorge Basadre Grohmann.

${ }^{2}$ Maestro en ciencias con mención en Gestión Ambiental y Desarrollo Sostenible, Biólogo Microbiólogo. Facultad de Ciencias.

Universidad Nacional Jorge Basadre Grohmann.
} 
obtained without using current- at room temperature and at $10 \mathrm{~h}$ within $35 \mathrm{~h}$ that it takes experimentation, likewise an area of polarization was determined graphically relating the power density versus current density between 20 and $80 \mathrm{~h}$ of experimentation which revealed : at the upper limit , a higher limit value on the curve obtained at $20 \mathrm{~h}$ corresponding to a power density $5000 \mathrm{E}-2 \mathrm{~mW} / \mathrm{m}^{2}$ and current density $40 \mathrm{E}-2 \mathrm{~mA} / \mathrm{m}^{2}$, and the lower limit, a higher limit value on the curve obtained at 0 hours corresponding to a power density $600 \mathrm{E}-2 \mathrm{~mW} / \mathrm{m}^{2}$ and current density of $35 \mathrm{E}-2 \mathrm{~mA} / \mathrm{m}^{2}$.

Keywords: Bioelectricity, Sacharomyces cerevisiae, heterofrofica, fermentation

\section{INTRODUCCIÓN}

La necesidad de encontrar fuentes de energía alternativa es cada vez más latente, una de estas posibilidades se puede localizar en los microorganismos procariotas y eucariotas, como son la gran diversidad de bacterias y levaduras respectivamente. Los microorganismos se encuentran en diferentes ambientes metabolizando diferentes sustratos. Es de mucho valor encontrar fuentes alternativas de energía eléctrica, aun sea en pequeña cantidad, utilizando estos microorganismos que a través de su metabolismo pueden generar energía y de esta manera ser aprovechados en diferentes usos por el hombre. Para obtener esta energía, se requiere el uso de celdas de combustible microbiana (MFC siglas en inglés) que consta de dos compartimientos, una anódica que contenga al ánodo y la otra catódica que contenga al cátodo. En la primera está destinado para contener los microorganismos, los cuales forman una biopelícula sobre el ánodo, que contribuyen con el flujo de electrones hacia el cátodo que contiene una solución amortiguadora, con lo cual se genera electricidad.

El uso de una celda de combustible microbiana puede contribuir reduciendo la crisis energética y aumentando la disponibilidad de agua. Una MFC es un dispositivo que utiliza microorganismos para convertir la energía química, contenida en un sustrato, en energía eléctrica. Esto es posible bajo condiciones adecuadas, donde determinados microorganismos electroactivos (bacterias, levaduras etc.) pasan los electrones producidos en su actividad metabólica a un electrodo en lugar de a un aceptor de electrones (como oxígeno o nitrato tal y como ocurre en los procesos de depuración natural). Este conocimiento está creando grandes logros para producir energía "verde" mediante la explotación de la biomasa contenida en las aguas residuales, utilizándose la materia orgánica contenida en éstas como combustible, además de depurarse las aguas contaminadas.

En este trabajo se tuvo como objetivo general generar electricidad en celdas de combustible microbiana utilizando células de Saccharomyces cerevisiae y sacarosa como sustrato; y como objetivos específicos: medir el potencial eléctrico, intensidad de corriente, densidad de corriente y densidad de potencial, así mismo determinar la curva de polarización.

\section{Aplicaciones de las celdas de combus- tible microbiano}

Producción de hidrógeno: Las MFCs pueden ser modificadas de manera que se utilicen para la producción de $\mathrm{H}_{2}$, por medio del proceso de electrólisis, esta modificación se puede realizar mediante la remoción del oxígeno de la cámara catódica y añadiendo un pequeño voltaje. Bajo condiciones normales de operación, los protones liberados por la reacción anódica migran al cátodo para combinarse con el oxígeno y formar agua. La generación de hidrógeno a partir de los electrones y protones producidos por el metabolismo de 
microorganismos en una MFC es termodinámica-mente desfavorable. Por ello la aplicación de un potencial externo para incrementar el potencial del cátodo en un circuito de MFC permite superar la barrera termodinámica. Así, los protones y electrones producidos por la reacción anódica se combinan en el cátodo para formar hidrógeno (esto se logra en ausencia de oxígeno). El potencial externo requerido teórico para una MFC es $110 \mathrm{mV}$, el cual es mucho menor que los $1210 \mathrm{mV}$ requeridos para llevar a cabo la electrólisis directa de agua a $\mathrm{pH}$ neutro, esto se debe a que algo de energía proviene del proceso de oxidación de la biomasa en la cámara anódica. (Du et al., 2007).

Potencialmente Las MFCs pueden producir alrededor de 8-9 $\mathrm{mol} \mathrm{H}_{2} / \mathrm{mol}$ glucosa comparado con el típico $4 \mathrm{~mol} \mathrm{H}_{2} / \mathrm{mol}$ glucosa alcanzado en fermentaciones convencionales. (Logan \& Reagan, 2006, Liu et al., 2005b) Entre las ventajas que presenta este sistema para la producción de hidrógeno se encuentra la mejora en eficiencia debida a la ausencia de oxígeno en la cámara catódica y que el hidrógeno producido puede ser acumulado y almacenado para su uso posterior.

Tratamiento de aguas residuales: recientemente, el tratamiento bioelectroquímico de aguas residuales ha emergido como una tecnología potencialmente interesante para la producción de energía de aguas residuales. El tratamiento bioelectroquímico de aguas residuales es basado en el uso de microorganismos electroquímicamente activos. Los microorganismos electroquímicamente activos son capaces de transferir electrones extracelularmente y pueden usar este mecanismo para transferir electrones a un electrodo mientras oxidan la materia orgánica presente en las aguas residuales.

Los microorganismos funcionan como un catalizador para la oxidación electroquímica de la materia orgánica, y el electrodo es por lo tanto descrito como un biánodo microbiano. El proceso de tratamiento bioelectroquímico de aguas residuales puede ser modificado por una conexión eléctrica del biánodo a un electrodo auxiliar (cátodo) que desempeñará una reacción de reducción.

Como resultado de esta conexión eléctrica entre el ánodo y el cátodo, las reacciones de los electrodos pueden ocurrir y los electrones pueden fluir del ánodo al cátodo produciendo así una corriente eléctrica (Rozendal et al., 2008). Las aguas residuales provenientes de la industria, la agricultura y de las casas contienen materia orgánica disuelta que requiere ser removida antes de ser descargada al medio ambiente. Actualmente, existen procesos para remover los contaminantes orgánicos presentes en esta agua de deshecho, la mayoría de estos procesos son tratamientos aeróbicos, los cuales consumen grandes cantidades de energía en el proceso de aeración. Sin embargo, el tratamiento de aguas residuales ha empezado a ser reconocido como una fuente renovable para la producción de electricidad lo cual podría emplearse para el mismo proceso de tratamiento de efluentes. (Aelterman et al., 2006, Logan \& Reagan, 2006).

Biorremediación: existe la posibilidad de modificar una MFC para utilizarla en procesos de biorremediación de suelos y aguas subterráneas. Aunque hay quienes argumentan que al ser modificadas ya no son MFC reales, ya que no producen electricidad, el principio de operación es similar y se usa la tecnología de las MFCs para cumplir estos objetivos. Las bacterias no son solo capaces de donar electrones a un electrodo, también pueden aceptar electrones del mismo.

Al modificar una MFCs convencional, esta no se usa para producir electricidad, en lugar de esto, se aplica una corriente al sistema para llevar a cabo la reacción deseada y así remover o degradar, por ejemplo $\mathrm{U}(\mathrm{VI})$ soluble a U(IV) insoluble. Es por esto que se ha propuesto su aplicación en sitios contaminados por metales pesados como $\mathrm{U}(\mathrm{VI})$. Una estrategia simple para prevenir posibles contaminaciones con uranio es adicionar un donador orgánico de electrones, como acetato a las aguas subterráneas.

El uso de esta tecnología para este fin ayuda 
con los problemas de contaminación ambiental, ya que no solo previene la movilidad del uranio, si no también, se puede extraer con bicarbonato cuando se retiran los electrodos de los lugares en los que operaron y posteriormente pueden reutilizarse dichos electrodos (Gregory \& Lovley, 2005).

Biosensores: Datos del medio ambiente pueden ser útiles para entender y modelar respuestas de los ecosistemas, aquí nace una aplicación importante para las MFCs, las cuales pueden emplearse para monitorear ambientes de tres maneras diferentes como se explica a continuación.

Los sistemas distribuidos en ambientes naturales requieren energía para su operación. Las MFCs pueden ser usadas como dispositivos que proporcionan dicha energía, particularmente en ríos y aguas profundas marinas donde es difícil acceder de manera continua al sistema para remplazar baterías. Celdas combustibles en sedimentos han sido desarrolladas para monitorear sistemas ambientales como son arroyos, ríos y océanos. (Logan \& Reagan, 2006b)

Otra aplicación de los biosensores es el monitoreo de compuestos tóxicos. Las bacterias muestran una baja actividad metabólica cuando son inhibidas por compuestos tóxicos. Esta inhibición causa una baja transferencia de electrones hacia el electrodo. De esta forma, un biosensor puede ser construido, inmovilizando una bacteria en el electrodo de una MFC y protegiéndola detrás de una membrana. Si un compuesto tóxico se difunde a través de la membrana, este puede ser medido por el cambio en el potencial del sensor. Dichos sensores pueden ser de utilidad como indicadores de sustancias tóxicas en ríos o en la entrada de plantas del tratamiento de aguas (Meyer et al., 2002,).

\section{Taxonomia de Saccharomyces cerevisiae Dominio: Eucaria \\ Reino: Fungi \\ Clase: Hemiascomycetes \\ Orden: Saccharomycetales \\ Familia: Saccharomycetaceae \\ Género: Saccharomyces}

\section{Especie: S. cerevisiae}

\section{Características de S. cerevisiae}

La levadura que crece en medios sólidos presenta un aspecto característico. Las colonias jóvenes son siempre húmedas y algo viscosas. En general son blanquecinas de color crema o rosadas. Al envejecer algunas de estas colonias cambian poco, pero otras se tornan secas y rugosas. Casi todas las especies crecen en forma de agregados sueltos de células aisladas que pueden ser globosas, ovoides más o menos piriformes o alargadas y casi cilíndricas.

Cuando crecen vigorosamente en cultivos, en portaobjetos, forman a menudo cadenas de células alargadas "pseudomicelio". En casi todas las especies de interés industrial el modo habitual de reproducción vegetativa es por gemación (Anderson,, Calderón y Vicente, 2000).

Los representantes del género Saccharomyces presentan células redondas ovales o alargadas, a menudo formando pseudomicelio; se reproducen por gemación multipolar; conjugación isogámica o heterogámica que puede o no estar precedida de formación del asca; contienen de 1 a 4 esporas por asca, por lo regular redondas u ovales, raras veces de otras formas; las esporas pueden conjugarse antes de iniciar el crecimiento, realizan intensa fermentación de la glucosa y otros azúcares, no utiliza los nitritos. Las especies de $S$. cerevisiae su aspecto colonial en medio sólido son blandas y húmedas, de color crema; células redondas ovales o algo piriformes en cultivos jóvenes que miden de 4 a 14 um por 3-7 um, con una proporción (largo: ancho) entre 1:1 y 2:1.

\section{Metabolismo de las levaduras $S$. cerevisiae}

Los microorganismos pueden dividirse, de acuerdo a sus necesidades ambientales, en tres grupos: aerobios estrictos, anaerobios estrictos y organismos facultativos a este último pertenecen las levaduras, que pueden cambiar su metabolismo de aeróbico (respiración) a anaeróbico (fermentación), en función del ambiente 
donde se encuentren. El metabolismo aerobio, capacita a las levaduras para oxidar completamente una cierta fracción del sustrato y extraer así la máxima energía par convertir el resto del sustrato en masa celular. Si el objetivo de la fermentación industrial es aumentar la biomasa, resulta una ventaja obvia tener un crecimiento aeróbico con utilización completa del sustrato por respiración, este metabolismo utiliza tres vía bioquímicas: glucólisis, ciclo de Krebs y cadena respiratoria.

En el metabolismo anaerobio no interviene la cadena respiratoria. En la industria, sin embargo, se suele denominar fermentación. Las fermentaciones son propias de los microorganismos como ciertas bacterias y levaduras; y es un proceso catabólico en el cual tanto el dador como el aceptor final de electrones son compuestos orgánicos. Generalmente estos dos compuestos son metabolitos de un único sustrato que durante el proceso se escinden, uno que actúa como dador de hidrógeno (se oxida) y otro que actúa como aceptor final de hidrógenos (se reduce) (Mateos, 2012). Por ejemplo en la fermentación alcohólica de la glucosa:

$\mathrm{C}_{6} \mathrm{H}_{12} \mathrm{O}_{6} \quad 2\left(\mathrm{CH}_{3}-\mathrm{CH}_{2} \mathrm{OH}\right)+2 \mathrm{CO}_{2}$

La glucosa, sin reaccionar con ninguna otra molécula, se ha escindido en una sustancia sin hidrógenos $\left(\mathrm{CO}_{2}\right)$, la sustancia oxidada, y en otra con tres hidrógenos por carbono $\left(\mathrm{CH}_{3}-\mathrm{CH}_{2} \mathrm{OH}\right)$, la sustancia reducida. Los enzimas de la fermentación son constitutivos y los enzimas de la respiración son inducibles. Las enzimas de la fermentación se encuentran en el citoplasma de la célula; las enzimas respiratorias están en los mitocondrias.

La cantidad de electrones y protones producidos depende del sustrato utilizado por los microbios. Las reacciones del electrodo en un compartimento MFC, si la sucrosa es el sustrato, son las siguientes:

Reacción anódica:

$\mathrm{C}_{12} \mathrm{H}_{22} \mathrm{O}_{11}+13 \mathrm{H}_{2} \mathrm{O} \rightarrow 12 \mathrm{CO}_{2}+48 \mathrm{H}^{+}+48 \mathrm{e}-$

Reacción catódica:

$12 \mathrm{O} 2+48 \mathrm{e}-+48 \mathrm{H}+\rightarrow 24 \mathrm{H} 2 \mathrm{O}$

En la preparación de electrodos de grafito, se enrollan con cable de cobre en un extremo de estas barritas. La parte del cable (extremo que va en la parte exterior), que no está enrollada en el grafito, se quita el aislante unos centímetros para permitir el contacto eléctrico con las conexiones del electroanalizador o multímetro. El cable enrollado en el grafito se aísla usando la resina epóxica de endurecimiento lento, los electrodos de grafito descritos se introducen en las cámaras anódicas y catódicas, previo pulido, para permitir la formación de un biofilm durante un tiempo determinado.

En cuanto a las membranas separadoras de las dos cámaras, estas membranas deben ser permeables para que los protones producidos en el ánodo y asi puedan migrar hacia el cátodo y de esta manera mantener la electro-neutralidad del sistema. Las membranas más utilizadas para este tipo de dispositivos generadores de electricidad son las de Nafion.

\section{MATERIALES Y MÉTODOS}

\section{Caracterización de la MFC}

La celda estuvo constituido por dos cámaras, de material de PVC, una anódica y la otra catódica, las cuales contuvieron los electrodos anódicos y catódicos respectivamente, separadas por una membrana de intercambio de protones (ver anexo).

Los ánodos y cátodos fueron de materiales conductivos, biocompatibles y químicamente estables en la solución del reactor, como es el carbón, disponible como placas de grafito compacto en barras, que han sido utilizados extensivamente como electrodos. Ambas cámaras, tanto el ánodo como el cátodo se separaron por una membrana de intercambio protónico, Nafion de 0,127 mm de espesor, que estuvo fijo a través de una unión universal.

Ambos compartimientos se cerraron con una tapa, de material de PVC, los cuales tuvieron aberturas para el paso de alambres conductores, estos conductores, en la parte interna de las cámaras estuvieron fijadas a barras de carbón y en la parte externa permitieron el paso de electrones y las mediciones con el multímetro. 
Ambas cámaras tuvieron medios líquidos, el ánodo tuvo $250 \mathrm{ml}$ medio de cultivo sacarosado y el cátodo $250 \mathrm{ml}$ de agua destilada; a este último, en la base de la cámara, se le insufló aire a través del motor aireador.

\section{Generación de electricidad}

-En la celda microbiana, en la cámara anódica, se colocó $250 \mathrm{ml}$ de medio de cultivo sacarosado al $8 \%$, a la cual se agregó la levadura Saccharomyces cerevisiae, hasta una concentración final de 0,4\%. En esta cámara luego se agregó una solución de azul de metileno al 1,6\%.

-A la cámara catódica se le agregó $250 \mathrm{ml}$ de agua destilada y conectó a un motor aireador que incorporó 1 VVM de aire para burbujear el agua destilada.

-La unión de ambas cámaras por la base, pero separados los contenidos de ambas cámaras por una membrana de Nafion, que fue colocada transversalmente dentro del tubo de unión hizo que pudieran los protones pasar desde la cámara anódica hacia la catódica.

-La celda de combustible microbiana se dejó que funcionara hasta 35 horas a temperatura ambiente, conectándose los conductores externamente de ambas cámaras, para que migraran los electrones desde el ánodo hacia el cátodo, y de ese modo se cerrara el circuito y generara electricidad.

\section{Medición de los parámetros de evaluación de electricidad generada en la MFC}

-Se midió, cada $5 \mathrm{~h}$ hasta las $35 \mathrm{~h}$, el potencial "E" (voltaje) de corriente discontinua "DC" generado en la MFC con un multímetro digital. Las mediciones se hicieron de mayor a menor voltaje, para evitar dañar el equipo de medición,

-En la medición de voltaje, se colocó una de las dos puntas de cables del multímetro (cable negro, negativo) también llamado "COM" sobre el alambre que provino del ánodo de la MFC y la segunda (cable rojo, positivo) del multímetro sobre el alambre que provino del cátodo de la MFC. Esto permitió que en el multímetro se registrara y se hiciera lectura del potencial en milivoltios $(\mathrm{mV})$. Este registro y lectura se hizo para cada medición sin colocar (0) y colocando resistencias de 10, 20, 50, 200, 500, 1000, 2 000, 10 000, 40000 y 100000 ohmios en diferentes momentos paralelo entre los cables externos del cátodo y ánodo de la MFC, solamente cuando se evaluó el potencial cada $5 \mathrm{~h}$.

Se calculó la intensidad de la corriente, I (Amperios), utilizando la fórmula de la ley de Ohms $\left(I=V \cdot R^{-1}\right)$, donde $V=$ voltaje, $y$ $\mathrm{R}=$ resistencia. Para cada valor de potencia obtenida en la evaluación y de resistencia utilizada se obtuvo un valor de intensidad de corriente.

-Se determinó la densidad de corriente, $\boldsymbol{j}$ (A . $\left.\mathrm{m}^{-2}\right)$, empleando la fórmula $j=\mid \mathbf{S}^{-1}$; donde $S$ (área en $\mathrm{m}^{2}$ del electrodo del ánodo) para cada valor de intensidad de corriente, I, calculada con los datos anteriores.

- Se estableció la densidad de potencia, Pd $\left(\mathbf{m W} \cdot \mathbf{m}^{-2}\right)$, empleando la fórmula $\mathbf{P d}=\mathbf{I V S}^{-1}$. para cada valor de intensidad de corriente y de potencia obtenida.

Finalmente se determinó la curva de polarización graficando los valores de densidad de potencia versus los de densidad de corriente para cada tiempo de evaluación $(0,5,10,20,25,30$ y $35 \mathrm{~h})$.

\section{RESULTADOS}

Cuadro $\mathbf{N}^{\circ}$ 1. Características iniciales de la celda de combustible microbiana utilizada en el experimento.

\begin{tabular}{|l|c|c|}
\hline Celda & Anódica & Catódica \\
\hline Temperatura $\left({ }^{\circ} \mathrm{C}\right)$ & 26 & 26 \\
\hline Azul de metileno $(\%)$ & 1,6 & - \\
\hline S. cerevisiae (\%) & 0,4 & \\
\hline Aireación VVM & - & 1 \\
\hline $\begin{array}{l}\text { Caldo papa sacarosa } \\
(\%)\end{array}$ & 4 & - \\
\hline
\end{tabular}

Fuente: elaboración propia 
Cuadro $\mathbf{N}^{0}$ 2. Valores de potencial de electricidad registrado en la MFC en sus tres repeticiones

\begin{tabular}{|c|c|c|c|c|}
\hline \multirow{2}{*}{$\begin{array}{c}\text { Tiempo } \\
(\mathrm{h})\end{array}$} & \multicolumn{2}{|c|}{ Potencial (mV) } & $\begin{array}{c}\text { Potencial } \\
\text { Promedio } \\
\text { (mV) }\end{array}$ \\
\hline 0 & 176 & 160 & 202 & 179,3 \\
\hline 5 & 185 & 193 & 208 & 195,3 \\
\hline 10 & 240 & 200 & 219 & 219,7 \\
\hline 15 & 233 & 169 & 141 & 181,0 \\
\hline 20 & 219 & 158 & 158 & 178,3 \\
\hline 25 & 192 & 158 & 119 & 156,3 \\
\hline 30 & 168 & 154 & 121 & 147,7 \\
\hline 35 & 159 & 154 & 123 & 145,3 \\
\hline
\end{tabular}

Fuente: elaboración propia

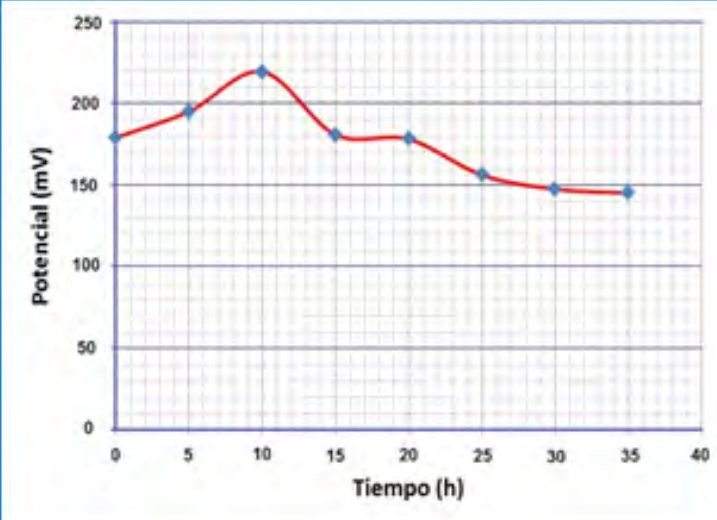

Fuente: elaboración propia

Figura $N^{0}$ 1. Curva de valores de potencial de electricidad versus el tiempo de generación de electricidad registrado en la Celda de Combustible Microbiana.

CUADRO $\mathbf{N}^{\circ} 3$. Valores máximos de Potencia ( E ), Intensidad de corriente (I ), Densidad de corriente $(\mathrm{J})$ y de Densidad de potencia $(\mathrm{Pd})$ a determinados valores de Resistencia ( $R$ ) y Tiempo ( $T$ ) de experimentación en la Celda de Combustible Microbiana.

\begin{tabular}{|cccccc|}
\hline & $\begin{array}{c}\text { Tiempo } \\
(\mathrm{h})\end{array}$ & $\begin{array}{l}\mathrm{E} \\
(\mathrm{v})\end{array}$ & $\mathrm{l}$ & $\mathrm{J})$ & $\mathrm{Jd}$ \\
$\left(\mathrm{mA} / \mathrm{m}^{2}\right)$ & $\begin{array}{l}\mathrm{Pd} \\
\left(\mathrm{mW} / \mathrm{m}^{2}\right)\end{array}$ \\
\hline $\mathrm{R}$ & 0 & 0,1793 & $20 \mathrm{E}-7$ & $42,79 \mathrm{E}-2$ & $605,5 \mathrm{E}-5$ \\
(ohmio) & & 0 & 10000 & 10000 & 0 \\
\hline $\mathrm{R}$ & 5 & 0,1138 & $50 \mathrm{E}-7$ & $106,97 \mathrm{E}-2$ & \multicolumn{2}{l}{$\begin{array}{l}-5 \\
\text { (ohmio) }\end{array}$} & & 10 & 40000 & 40000 & 10 \\
\hline
\end{tabular}

\begin{tabular}{|c|c|c|c|c|c|}
\hline $\begin{array}{c}\mathrm{R} \\
\text { (ohmio) }\end{array}$ & 10 & $\begin{array}{c}0,2197 \\
0\end{array}$ & $\begin{array}{l}50 E-7 \\
40000\end{array}$ & $\begin{array}{c}106,97 E-2 \\
40000\end{array}$ & $\begin{array}{l}2968,9 E \\
-5 \\
10\end{array}$ \\
\hline $\begin{array}{c}\mathrm{R} \\
\text { (ohmio) }\end{array}$ & 15 & $\begin{array}{c}0,1218 \\
10\end{array}$ & $\begin{array}{r}50 E-7 \\
40000\end{array}$ & $\begin{array}{c}106,97 E-2 \\
40000\end{array}$ & $\begin{array}{lc}3173,9 \mathrm{E} \\
-5 \\
\\
10\end{array}$ \\
\hline $\begin{array}{c}\mathrm{R} \\
\text { (ohmio) }\end{array}$ & 20 & $\begin{array}{c}0,1783 \\
0\end{array}$ & $\begin{array}{r}50 E-7 \\
40000\end{array}$ & $\begin{array}{c}106,97 E-2 \\
40000\end{array}$ & $\begin{array}{l}4960,3 \mathrm{E} \\
-5 \\
20\end{array}$ \\
\hline $\begin{array}{c}\mathrm{R} \\
\text { (ohmio) }\end{array}$ & 25 & $\begin{array}{c}0,1563 \\
0\end{array}$ & $\begin{array}{r}100 E-7 \\
100000\end{array}$ & $\begin{array}{c}213,95 E-2 \\
100000\end{array}$ & $\begin{array}{ll} & 4776,6 \mathrm{E} \\
-5 & \\
& 20\end{array}$ \\
\hline $\begin{array}{c}\mathrm{R} \\
\text { (ohmio) }\end{array}$ & 30 & $\begin{array}{c}0,1477 \\
0\end{array}$ & $\begin{array}{c}100 E-7 \\
100000\end{array}$ & $\begin{array}{c}213,95 E-2 \\
100000\end{array}$ & $\begin{array}{l}4351,8 \mathrm{E} \\
-5 \\
20\end{array}$ \\
\hline $\begin{array}{c}\mathrm{R} \\
\text { (ohmio) }\end{array}$ & 35 & $\begin{array}{c}0,1453 \\
0\end{array}$ & $\begin{array}{r}50 E-7 \\
40000\end{array}$ & $\begin{array}{c}106,97 E-2 \\
40000\end{array}$ & $\begin{array}{ll}3810,1 \mathrm{E} \\
-5 & \\
& 20\end{array}$ \\
\hline
\end{tabular}

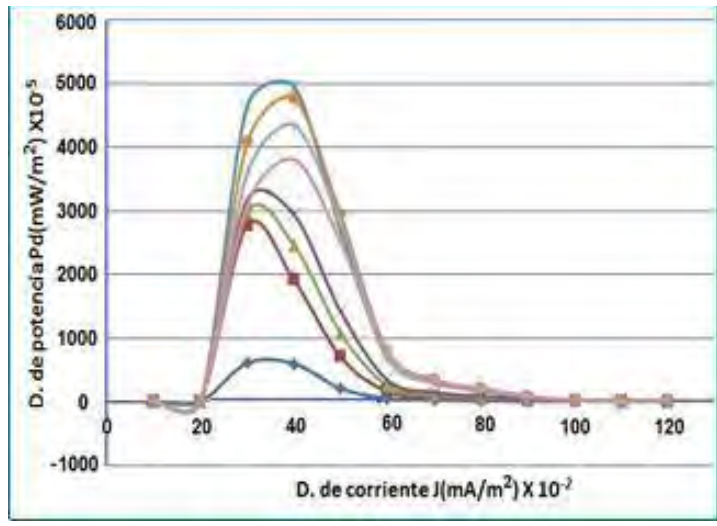

$+0 h-5 h-10 h+15 h-20 h+25 h+30 h-35 h$

Figura $N^{\circ}$ 2: Curva de polarización relacionando la densidades de potencia versus la densidades de corriente obtenidos con los diferentes valores de resistencia trabajados $(0,10,20,50,200,500,1000,2$ $000,10000,40000$ y 100000 ohmios) a las $0,5,10,20,25,30$ y $35 \mathrm{~h}$ en que se realizaron las evaluaciones de la experimentación.

\section{DISCUSIÓN}

La celda de combustible microbiano utilizada consiste de un ánodo y un cátodo separados por una membrana permeable específicamente de protones. En la cámara anódica las levaduras $S$. cerevisiae oxidan el combustible (sustrato sacarosa) generando electrones y protones, estos protones y electrones se transfieren al compartimiento catódico, los protones pasan a través de la membrana catiónica, mientras que, los electrones se mueven a través del circuito 
externo, generando de este modo corriente eléctrica. Se realiza la reducción en el compartimiento catódico, y esta se da por el oxígeno suministrado por aireación a través de un motor externo. En cuanto a los electrones estos requieren de un "acarreador" que puedan trasladar los electrones desde las células hacia los electrodos y estas a su vez la trasladan externamente desde los electrodos del ánodo hacia la cámara catódica, Los electrones no pueden ser transferidos de los sistemas de transporte de electrones normales de las células al electrodo, por su naturaleza no conductora de

las estructuras de la superficie celular de $S$. cerevisiae, por lo tanto el empleo de estos mediadores electroquímicos como azul de metileno, transfirieron electrones desde el interior de las levaduras hacia el electrodo del ánodo y de esta hacia el electrodo del cátodo a través de un alambre conductor, generándose de este modo energía en forma de electricidad a partir de esta transferencia de electrones entre ambas cámaras.

El voltaje obtenido en este proceso fue de 219,7 mV como promedio más alto y de $145,3 \mathrm{mV}$ como el valor más bajo, que se observa en el cuadro 2 y figura 1, estos resultados fueron mayores a los encontrados por Sharma \& Bulchandani, 2011, y Castillo \& Tito, 2012, en la cual obtuvieron valores de 170 y $151 \mathrm{mV}$ respectivamente, estos resultados dependieron de la disponibilidad de sustrato en el medio de fermentación como es la sacarosa que fue consumiéndose por el metabolismo propio de las células, como ser su multiplicación de las mismas células y para el mantenimiento de sus procesos vitales. Otro de los motivos por el cual se disminuyó la generación de electrones fue por que el proceso es denominado discontinuo o proceso en "batch", en la cual se trabajó con una cantidad fija de sustrato sacarosa, iniciándose con una concentración de $4 \%$, por lo tanto las células de $S$. cerevisiae consumieron este sustrato, aumentando su concentración en unidades celulares. En cuanto a la baja cantidad de electricidad generada por este sistema se puede deber a perdidas óhmicas, por activación de los microorganismos y por la disminución de la concentración de substrato según Saavedra, 2012.

Con los datos de potencial (E) utilizando resistencias, se obtuvo una curva de polarización, esto con la finalidad de caracterizar la corriente en función de potencial (cuadro 3)(figura 2), por lo general se utiliza la parte superior de la curva, de polarización, registrándose al inicio del experimento $(0 \mathrm{~h})$ un valor de $605,50 \times 10^{-5}$ $\mathrm{mW} / \mathrm{m}^{2}$, este valor fue aumentado con el pasar de las horas hasta llegar a un máximo de potencia de $4960,25 \times 10^{-5} \mathrm{~mW} / \mathrm{m}^{2}$ a las $20 \mathrm{~h}$ de iniciado el experimento, y que luego esta potencia fue disminuyendo hasta $3101,44 \mathrm{~mW} / \mathrm{m}^{2}$ a las $35 \mathrm{~h}$ de iniciada la experimentación. Esta tendencia de declinación de la curva de polarización, se debe, al igual que en el voltaje, a pérdidas óhmicas que se relaciona con la resistencia al flujo de electrones por parte del electrodo, también a las conexiones que se realizaron en los electrodos y la distancia entre los electrodos. Así como también a la perdida de energía por la disminución de la concentración del sustrato sacarosa o al transporte de masas. En este trabajo en células de levaduras se produjeron las reacciones de oxido-reducción, para que se realice la transferencia de electrones hacia los electrodos, este compuesto puede estar en la superficie de las células. La pérdida por disminución de sacarosa se dió por el metabolismo de las levaduras y por el transporte de los electrones desde el sustrato, medio de cultivo papa sacarosado, a través de la cadena del transporte de electrones, hasta el aceptor final de electrones como es el oxígeno u otro compuesto, con potencial de reducción más alto (Sacco et I, 2012) y (Logan et al., 2006). Otro aspecto que se tendría que tomar en cuanta son los mediadores solubles para transferir electrones desde las células hacia el electrodo que en este trabajo fue de 1,6 \% por debajo de los utilizados por Sharma \& Bulchandani, 2011, que tiene sus desventajas al aumentar su concentración debido a que podría inactivar a las células y 
si es muy baja concentración acarrearía menos electrones.

\section{CONCLUSIONES}

1. A través de la celda de combustible microbiana se obtuvo un voltaje máximo de 0,2197 V sin utilizar resistencia de corriente (asumiendo el valor de la resistencia igual a cero) empleando células de Saccharomyces cerevisiae y sacarosa en medio de cultivo líquido, a temperatura ambiente, a las 10 horas del lapso de 35 horas en que duró la experimentación.

2. Se obtuvo un valor máximo de intensidad de corriente, $100 \mathrm{E}-7$ y densidad de corriente, 213,95E-2, ambos a las 25 horas y con 100000 ohmios de resistencia; así mismo un valor máximo de densidad de potencia, 4960,25E-5 a las 20 horas con 20 ohmios de resistencia.

3. Se determinó un área de polarización, relacionando gráficamente la densidad de potencia versus densidad de corriente, entre las 20 y 80 horas de experimentación donde se evidenció: en el límite superior, un valor tope más alto de la curva obtenida a las 20 horas correspondiente a una densidad de potencia de $5000 \mathrm{E}-2 \mathrm{~mW} / \mathrm{m}^{2}$ y de densidad de corriente de $40 \mathrm{E}-2 \mathrm{~mA} / \mathrm{m}^{2} ; \mathrm{y}$ en el límite inferior, un valor tope más alto de la curva obtenida a las 0 horas correspondiente a una densidad de potencia de $600 \mathrm{E}-2 \mathrm{~mW} / \mathrm{m}^{2}$ y de densidad de corriente de $35 \mathrm{E}-2 \mathrm{~mA} / \mathrm{m}^{2}$.

4. Se determinó una curva de polarización para este proceso comprobándose que a partir de las 20 horas de iniciada la experimentación esta empieza a tener pérdidas por disminución de sustrato o transporte de masas.

\section{REFERENCIAS BIBLIOGRÁFICAS}

Aelterman, P., Rabaey, K., Pham, H., Boon, N. Y Verstraete. W. 2006. Continuous electricity generation at high voltages and currents using stacked microbial fuel cells. Environ. Sci. Technol. 40: 3388-3394.

Anderson, P., Calderón, M. Y Vicente P.
2000. Microbiología Alimentaria. Metodología analítica para alimentos y bebidas. 2da edic. España.

Busalmen, J., Esteve-neñez, A. Y Feliu J. 2008. Whole cell electrochemistry of electricity - producing microorganisms evidence an adapttation for optimal exocellular electron transport. Environ. Sci. Technol. 2008, 42, 2445-2450. Alicante, Spain.

Castillo, D. Y Tito, C. 2012. Diseño y operación de una celda generadora de electricidad microbiana. Laboratorio de micología, virología y biotecnología, ESBI/FACI/UNJBG. Tacna, Perú.

Cedrón, J.; Landa, V.; Robles, J. \& SAKIYAMA, D. 2011. Química general, Celdas galvánicas o celdas voltaicas. Perú.

Cheng, S., Liu, H. Y Logan, B. 2006. Increased power generation in a continuous flow MFC with advective flow through the porous anode and reduced electrode spacing. Environ. Sci. Technol. 40:24262432.

Du, Z., Li, H. Y Gu, T. 2007. A estate of the art review on microbial fuel cells: A promising technology for wastewater treatment and bioenergy. Biotechnol. Adv. 25:464-482.

Escalante, E. 2010. Producción continua de etanol utilizando Sacharomyces cerevisiae inmovilizada en alginato de calcio en un biorreactor tipo tanque. EAP. de Ingeniería Química. UNJBG, Tacna perú.

Gorby, Y Col. 2006 Electrically conductive bacterial nanowires produced by Shewanella oneidensis strain MR-1 and other microorganisms. Proc Natl Acad Sci U SA. 103:11358-11363.

Gregory, K. Y Lovley, D. 2005. Remediation and recovery of uranium from contaminated subsurfaces environments with electrodes. Environ. Sci. Technol. 39:8943-8947.

Liu, H. Y Logan, B. 2004. Electricity generation using an aircathode single chamber microbial fuel cell in the presence 
and absence of a proton exchange membrane. Environmental Science \& Technology. 38, 4040-4046. HAU, H. Y Gralnick, J. 2007. Ecology and biotechnology of the genus Shewanella. Annu. Rev. Microbiol. 61:237-258.

Logan, B. Y Regan, J. 2006b. Electricityproducing bacterial communities in microbial fuel cells. Trends Microbiol. 14:512-518.

Logan, et. al 2006. Microbial fuel cells: methodology and technology. Environ Sci Technol. 40:5181-92.

Logan, B. 2004. Extracting hydrogen and electricity from renewable resources. Env. Sci. Technol. 38: 160A-167a

Logan, B. 2005. Electricity and hydrogen production using microbial fuel cell-based technologies. Engineering Envirom. Institute. Penn State Univesity.

Lovley, D. 2008. The microbe electric: conversion of organic matter to electricity. Current Opinion in Biotech. 2008, 19:1-8. COBIOT-578.

Martos, M. 2005. Ingeniería e innovación, las pilas de combustible, un posible futuro energético. España.

Mateos, P. 2012. Micoorganismos heterótrofos. Mecanismos de obtención de energía por microrganismos quimioheterótrofos.. Departamento de Microbiología y genética. Universidad de Salamanca. España.

Meyer, R., Larsen, L. Y Revsbech, N. 2002. Microscale biosensor for measurement of volatile fatty acids in anoxic environments. Appl. Environ. Microbiol. 68:1204-1210.

Nevin, K. Y Lovley, D. 2002. Mechanisms for
$\mathrm{Fe}$ (III) oxide reduction in sedimentary environments Geomicrobiol. J. 19:141-159.

Reguera, G., Mccarthy, K., Mehta, T. Y Nicoll, J. 2005. Biotechnol. 26:450-459.

Rozendal, R., Hamelers, H., Rabaey, K., Keller, J. Y Buisman, C. 2008. Towards practical implementation of bioelectrochemical wastewater treatment. Trend. Biotechnol. 26:450-459

Saavedra A. 2012. Producción de bioelectricidad usando celdas de combustible microbiana (MFC). Universidad de las Naciones Unidas. Universidad de Buenos Aires.

Sacco E, Et Al. (2012) Comparative analysis of the molecular mechanisms controlling the initiation of chromosomal DNA replication in yeast and in mammalian cells. Biotechnol Adv30(1):73-98

Sharma V. K. \& Bulchandani B. D. 2011. Comparative study of various substrates and microorganisms in a laboratory designed microbial fuel cell. Int. J. of Buss. and Engg. Res., 4, 49-59.

Tulio, M., \& Mesa, L. (2004). Principios de funcionamiento y construcción de una celda de combustible de ácido fosfórico. Scientia e $t$ Technica, $125-130$. http://www.tecnicaindustrial.es/TIFrontal/a1242-las-pilas-combustible--posible-futuroenergetico.aspx

You, S., Zhao, Q. Y Jiang, J.q. 2006. Biological wastewater treatment and simultaneous generating electricity from organic wastewater by microbial fuel cell. Huan Jing Ke Xue. 27:1786-17 